Provided for non-commercial research and education use. Not for reproduction, distribution or commercial use.

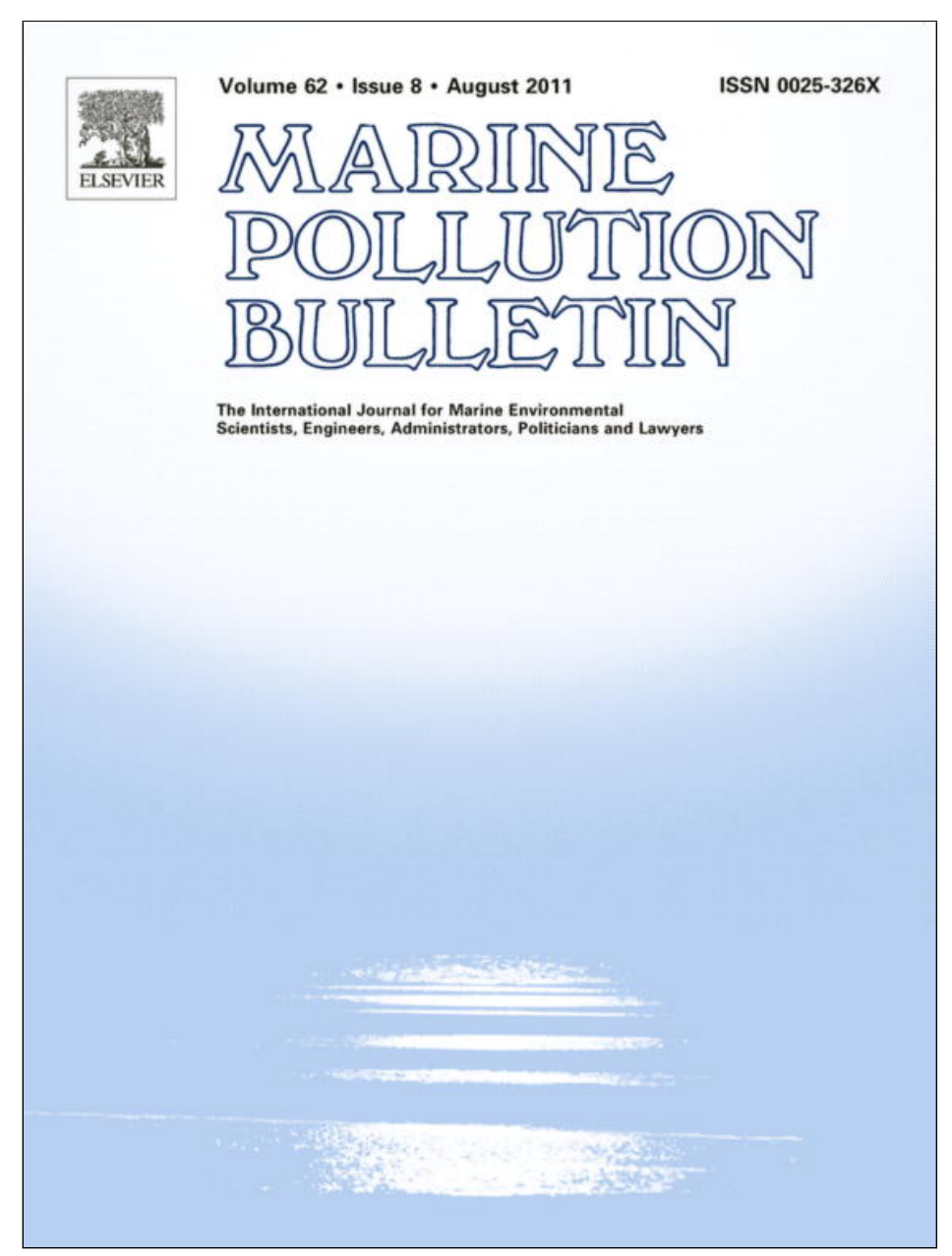

This article appeared in a journal published by Elsevier. The attached copy is furnished to the author for internal non-commercial research and education use, including for instruction at the authors institution and sharing with colleagues.

Other uses, including reproduction and distribution, or selling or licensing copies, or posting to personal, institutional or third party websites are prohibited.

In most cases authors are permitted to post their version of the article (e.g. in Word or Tex form) to their personal website or institutional repository. Authors requiring further information regarding Elsevier's archiving and manuscript policies are encouraged to visit:

http://www.elsevier.com/copyright 
Baseline

\title{
Characterization of organic matter in sediment cores of the Todos os Santos Bay, Bahia, Brazil, by elemental analysis and ${ }^{13} \mathrm{C}$ NMR
}

\author{
A.B. Costa ${ }^{\text {a }}$, E.H. Novotny ${ }^{\text {b }}$, A.C. Bloise ${ }^{\text {, }}$, E.R. de Azevedo ${ }^{c}$, T.J. Bonagamba ${ }^{c}$, M.R. Zucchi ${ }^{\text {a,* }}$, V.L.C.S. Santos ${ }^{\text {d }}$, \\ A.E.G. Azevedo ${ }^{\mathrm{a}}$ \\ ${ }^{a}$ Centro de Pesquisa em Geofísica e Geologia, Instituto de Física, Universidade Federal da Bahia, 40170-115 Salvador, BA, Brazil \\ ${ }^{\mathrm{b}}$ Embrapa Solos, Rua Jardim Botânico, 1024, 22460-000 Rio de Janeiro, RJ, Brazil \\ ${ }^{\mathrm{C}}$ Instituto de Física de São Carlos, Universidade de São Paulo, Caixa Postal 369, 13560-970 São Carlos, SP, Brazil \\ ${ }^{\mathrm{d}}$ Instituto de Química, Universidade Federal da Bahia, 40170-290 Salvador, BA, Brazil
}

\section{A R T I C L E I N F O}

\section{Keywords:}

Autoregressive Integrated Moving Average

Principal Component Analysis

Cores

Environmental impact

Refinery

\begin{abstract}
A B S T R A C T
The impact of human activity on the sediments of Todos os Santos Bay in Brazil was evaluated by elemental analysis and ${ }^{13} \mathrm{C}$ Nuclear Magnetic Resonance $\left({ }^{13} \mathrm{C}\right.$ NMR). This article reports a study of six sediment cores collected at different depths and regions of Todos os Santos Bay. The elemental profiles of cores collected on the eastern side of Frades Island suggest an abrupt change in the sedimentation regime. Autoregressive Integrated Moving Average (ARIMA) analysis corroborates this result. The range of depths of the cores corresponds to about 50 years ago, coinciding with the implantation of major onshore industrial projects in the region. Principal Component Analysis of the ${ }^{13} \mathrm{C}$ NMR spectra clearly differentiates sediment samples closer to the Subaé estuary, which have high contents of terrestrial organic matter, from those closer to a local oil refinery. The results presented in this article illustrate several important aspects of environmental impact of human activity on this bay.
\end{abstract}

(C) 2011 Elsevier Ltd. All rights reserved.

\section{Introduction}

The chemical composition of sedimentary organic matter may vary with climate, proximity to the shore and the relative contributions of marine and continental organic matter residues. Anthropic influence on the environment modifies the composition and concentration of the organic matter, potentially affecting the local biota. Carbon and nitrogen are the two main components of the organic matter. The organic carbon content in surface sediment depends on a series of factors such as sedimentary characteristics, rate of microbial degradation, water column productivity and proportion of terrestrial inputs. Organic matter from higher plants has low nitrogen content and thus a high carbon/nitrogen $(\mathrm{C} / \mathrm{N})$ ratio. Therefore, higher $\mathrm{C} / \mathrm{N}$ ratios in marine sediments indicate a predominantly terrestrial source of organic matter, whereas sediments rich in marine organic matter have lower $\mathrm{C} / \mathrm{N}$ ratios (Burone et al., 2003). According to Bordovsky (1965), marine sediments near river exhibit the highest $\mathrm{C} / \mathrm{N}$ ratios, indicating the input of terrestrial material into the area. The input of inorganic nitrogen by sewage can contribute to lowering the $\mathrm{C} / \mathrm{N}$ ratio.

Solid-state ${ }^{13} \mathrm{C}$ NMR spectroscopy provides techniques that enable reliable identification of insoluble sediment organic

\footnotetext{
* Corresponding author. Tel.: +55 74 32636680; fax: +55 7132350002.

E-mail address: mrzucchi@ufba.br (M.R. Zucchi).
}

structures (Patience and Wilson, 1990). To achieve a high sensitivity in this task, a combination of ${ }^{1} \mathrm{H}-{ }^{13} \mathrm{C}$ cross-polarization with radiofrequency ramp (ramped-CP), magic-angle spinning (MAS) and high power ${ }^{1} \mathrm{H}$ dipolar decoupling (DEC) is normally used (Peersen et al., 1993). The ${ }^{13} \mathrm{C}$ ramped-CP/MAS method allows carbons associated with distinct molecular groups, such as alkyl, methoxyl, O-alkyl, di-O-alkyl, aromatic, and carboxyl (Hedges and Oades, 1997), to be distinguished in the organic fraction of marine sediment.

The sedimentation regime in Todos os Santos Bay has undergone many important changes due to the impact of human activities. The sediment cores studied in this article were collected in the northern part of the bay, three in the clayey region near the harbor of Madre de Deus and the Mataripe Refinery, where many oil refining and transport operation are concentrated, and three near the estuary of the Subaé River and the old oil-drilling extraction field, Dom João.

In this article, a set of experimental data obtained by various techniques are reported and analyzed statistically, to estimate the impact of human activity on this bay.

\section{Materials and methods}

\subsection{Study site}

Todos os Santos Bay, Bahia, is the largest Brazilian bay, with an area of $1086 \mathrm{~km}^{2}$. It is located between west longitudes $38^{\circ} 25^{\prime}$ and 
$38^{\circ} 45^{\prime}$, and south latitudes $12^{\circ} 35^{\prime}$ and $13^{\circ} 00^{\prime}$ (Fig 1 ). The sites investigated are located at the northern end part of the Bay, where the dominant material in the sediments is a very fine mud. Mangroves and the estuaries of rivers characterize the coastline in this region.

\subsection{Sampling}

The sediments were sampled by one core at each site (T1, T2, T3, T4, T5, and T6), as illustrated in Fig. 1. The first set of cores (T1, T2, and T3) was collected from three sites in the vicinity of the Mataripe refinery and Madre de Deus harbor, to the east of Frades Island. The other three sites (T4, T5, and T6) were located west of Frades Island, close to the Subaé River estuary (Fig. 1). These sites were chosen for their proximity to industrial activities and the influence of the Subaé (main) and Paraguaçu rivers. The core samples were collected manually by inserting a tube, about $1 \mathrm{~m}$ long and $0.075 \mathrm{~m}$ in diameter, into the sediment. The water depth over the sampling sites varied between 2 and $10 \mathrm{~m}$. The cores were maintained at $0{ }^{\circ} \mathrm{C}$ in the boat and in transit and at $-20^{\circ} \mathrm{C}$ in the laboratory. They were cut into $2.5-\mathrm{cm}$ sections; freeze dried and stored at $-20^{\circ} \mathrm{C}$ until analyzed.

\subsection{Elemental analysis}

The determination of total organic carbon (TOC), nitrogen $(\mathrm{N})$, and sulfur (S) was carried out in carbonate-free sediment samples treated with $10 \mathrm{~mL}$ of $1 \mathrm{M}$ hydrochloric acid (Ryba and Burgess, 2002 and Burone et al., 2003). Portions of each sample (15$20 \mathrm{mg}$ ) were weighed in small tin capsules and analyzed in a CHNS Thermo Finnigan Flash EA 1112 series elemental analyser. The calibration was verified by measuring samples of certified reference marine sediment NIST $1941 \mathrm{~b}$, treated in the same way as the samples.

Because of the characteristics of depth sampling, the longitudinal data analysis approach was adopted, using an Autoregressive Integrated Moving Average (ARIMA) model with a gradual permanent impact, in order to model the anthropic impact, 50 years ago, through the alteration in the sediment composition. This model takes autocorrelation into account and has the following fitting parameters: the initial value (intercept); the statistical significance of the intervention, in this case the implementation of a refinery; the rate of alteration due to the intervention $(\omega)$; the time taken for the new level to be stabilized $(\delta)$ and the asymptotic change, i.e. the increase/decrease of the initial level after the series is stabilized.

After the stationary state, the ARIMA model was adjusted for each analyzed element ( $\mathrm{C}, \mathrm{N}$, and $\mathrm{S}$ ) and for the ratios $\mathrm{C} / \mathrm{N}$ and $\mathrm{C} /$ $\mathrm{S}$. All the adjustments were performed with only one autoregressive parameter - ARIMA $(1,0,0)$. The adjusted parameters (intercept, final value, $\delta, \omega$, and asymptotic change) of the sites were compared in pairs by Student's $t$-test at a $5 \%$ level of significance. The variance homogeneity was assessed by the $F$ test and, according to the results, the appropriate $t$-value was used.

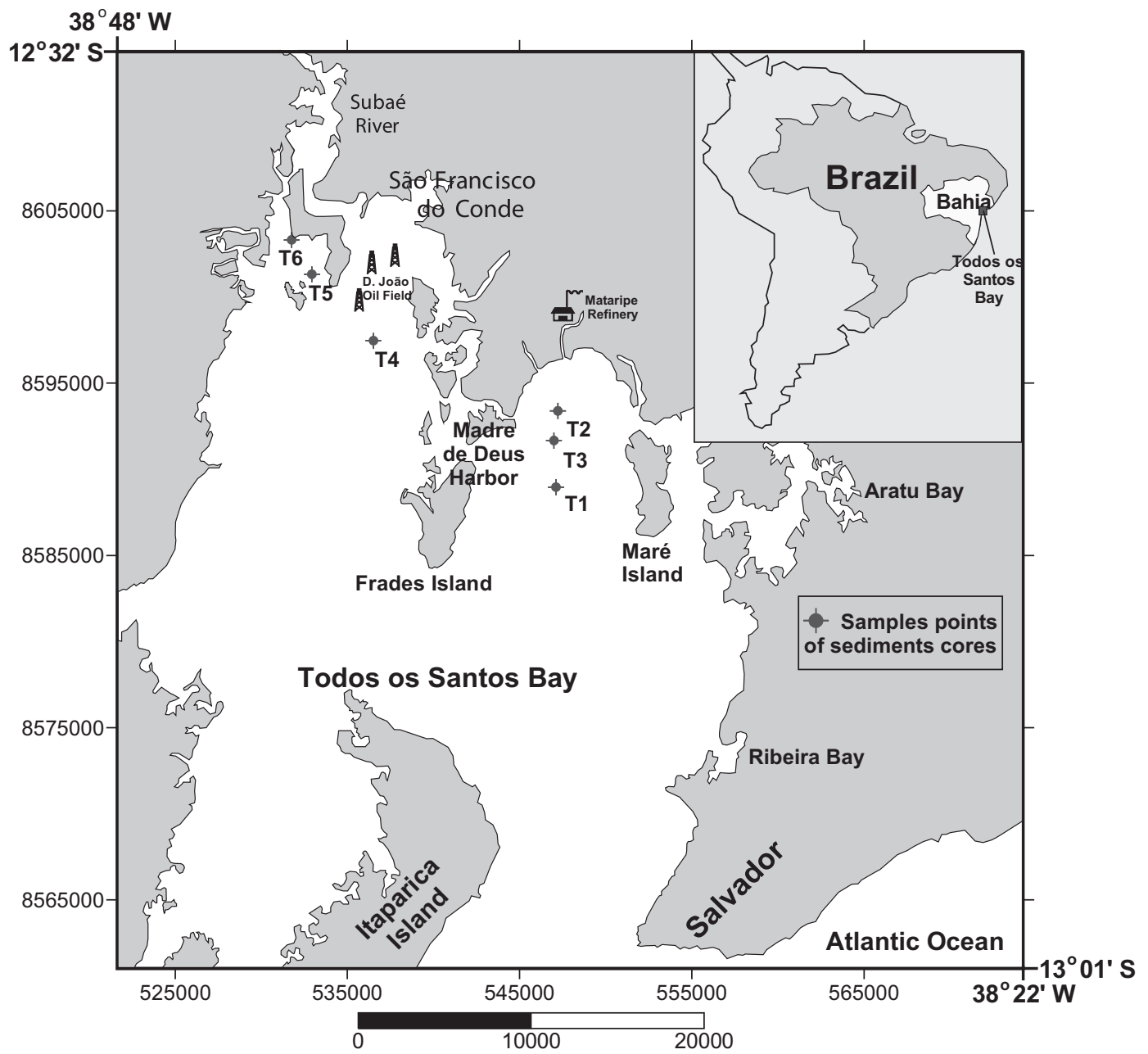

Fig. 1. Todos os Santos Bay map with sediments cores localization. 

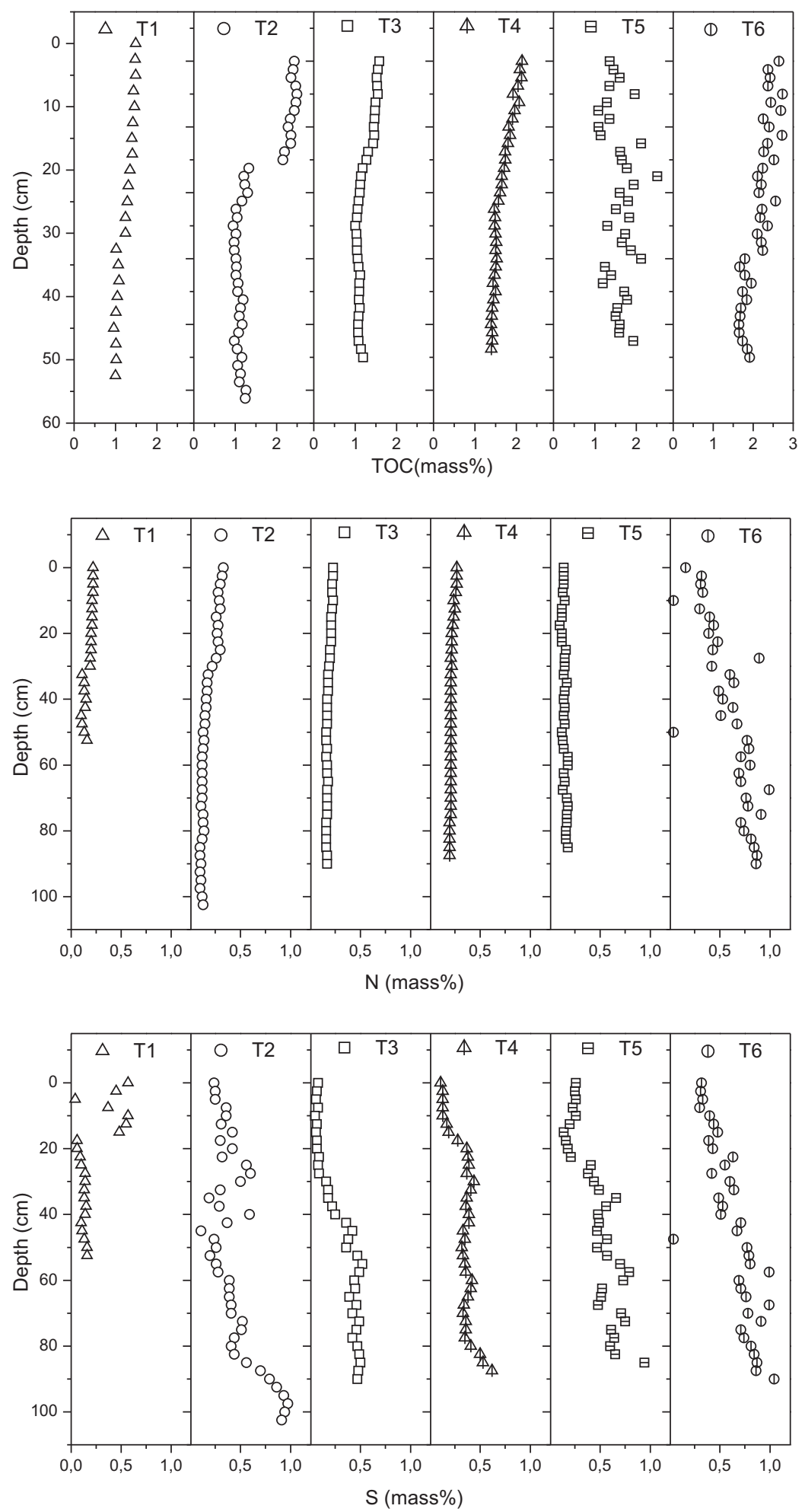

Fig. 2. Profiles of total organic carbon (TOC), nitrogen (N) and sulfur (S) in the cores. Error bars are approximately of the same size of the symbols.

\section{4. ${ }^{13}$ C NMR spectroscopy}

Part of the top slice and bottom slice of each core were prepared for ${ }^{13} \mathrm{C}$ NMR analysis. Samples were initially treated with $1 \mathrm{M} \mathrm{HCl}$, to extract the inorganic carbonates, and then with $10 \% \mathrm{HF}$, to extract silicates and concentrate the organic material. According to Gélinas et al. (2001), this treatment offers a reasonable compromise between maximal mineral dissolution efficiency and minimal organic carbon losses. NMR measurements were performed with a Unit Inova (Varian) spectrometer operating at 400.0 and $100.5 \mathrm{MHz}$ for ${ }^{1} \mathrm{H}$ and ${ }^{13} \mathrm{C}$, respectively. The spectra were acquired by the ramped$\mathrm{CP} / \mathrm{MAS}$ method, with linear amplitude variation of the ${ }^{1} \mathrm{H}$ pulse (Peersen et al., 1993, Cook et al., 1996, Dria et al., 2002). All measurements were performed under $6 \mathrm{kHz}$ MAS spinning frequency. The strength of the ${ }^{1} \mathrm{H}$ decoupling field applied during signal acquisition was $\sim 60 \mathrm{kHz}$ and the $\mathrm{CP}$ contact time was $1 \mathrm{~ms}$. 

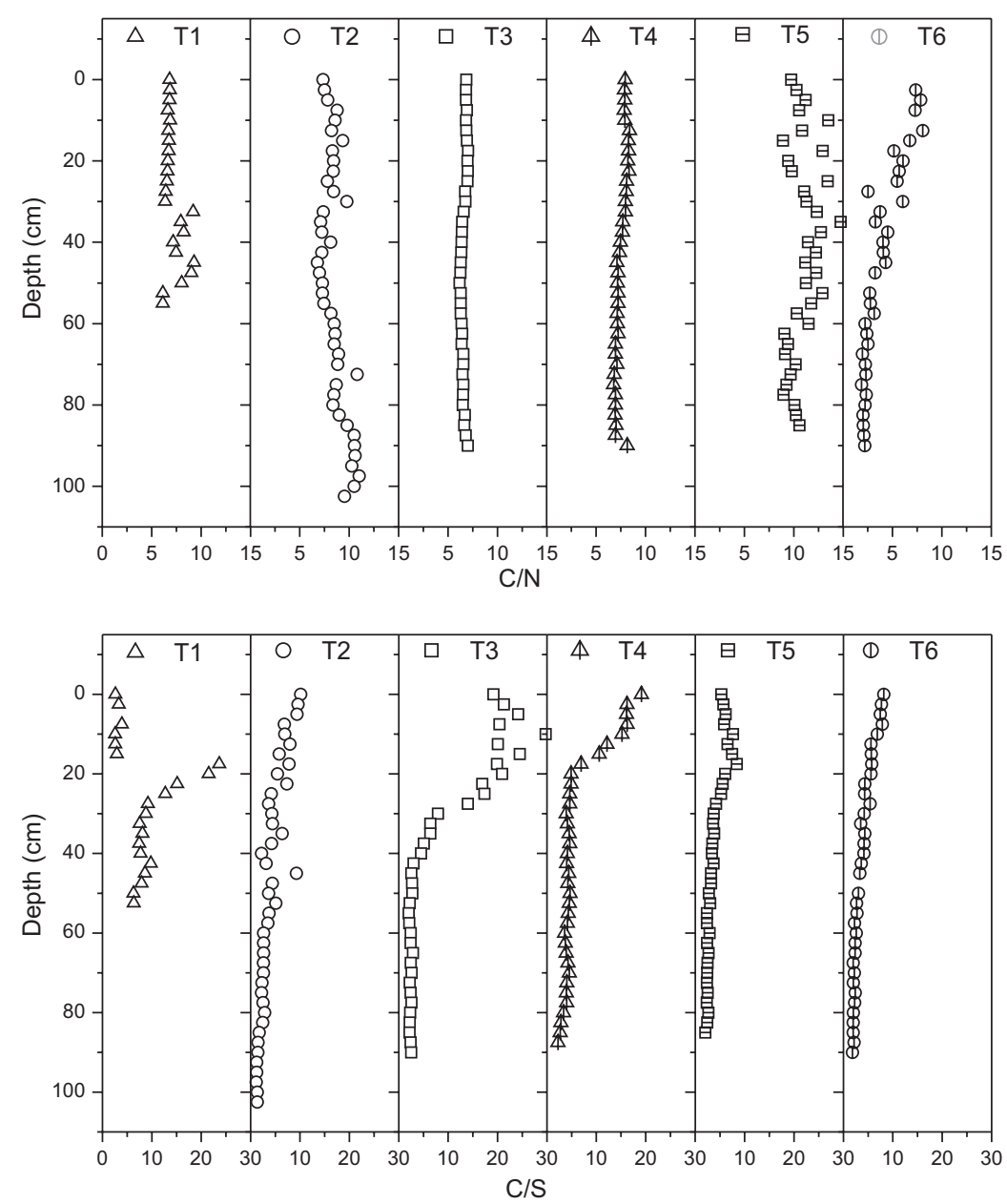

Fig. 3. Profiles of mass ratio of carbon to nitrogen $(\mathrm{C} / \mathrm{N})$ and carbon to sulfur $(\mathrm{C} / \mathrm{S})$. Error bars are approximately of the same size of the symbols.

Table 1

Depth of the statistically significant intervention.

\begin{tabular}{llllll}
\hline Core & C & N & S & C/N & C/S \\
\hline T1 & $32.5-35.0$ & $32.5-35.0$ & $17.5-20.0$ & $32.5-35.0$ & $27.5-30.0 / 17.5-20.0$ \\
T2 & $30.0-32.5$ & $30.0-32.5$ & $45.0-47.5$ & $30.0-32.5$ & $30.0-32.5$ \\
T3 & $32.5-35.0$ & $40.0-42.5$ & $40.0-42.5$ & $32.5-35.0$ & $30.0-32.5$ \\
T4 & $45.0-47.5$ & $62.5-65.0$ & $20.0-22.5$ & $47.5-50.0$ & $20.0-22.5$ \\
T5 & ns & ns & ns & ns & $60.0-62.5$ \\
T6 & $60.0-62.5$ & $60.0-62.5$ & $60.0-62.5$ & $60.0-62.5$ & $60.0-62.5$ \\
\hline
\end{tabular}

Multivariate statistics encompasses a set of techniques to analyze data, in which all or several variables are simultaneously assessed. Principal Component Analysis (PCA) is one of these techniques; it reduces the number of variables and detects a data structure that reflects the way they are related (Novotny et al., 1999).

This approach was applied to the ${ }^{13} \mathrm{C}$ NMR spectra (Novotny et al., 2008) in the present study, with the purpose of analyzing the distribution of organic chemical groups from the top to the bottom of each core, to enable the organic matter distributions to be correlated with the human activities.

\section{Results and discussion}

\subsection{Elemental analysis}

Fig. 2 shows the percent mass of TOC, N and $\mathrm{S}$ in the sediment cores T1, T2, T3, T4, T5, and T6, located as indicated in Fig. 1. The TOC values vary from $\sim 0.95$ to $2.70 \mathrm{wt}$.\% in the cores, the highest values being observed in core $\mathrm{T} 6$. The $\mathrm{N}$ contents range from 0.10 to $0.33 \mathrm{wt}$.\% in cores, decreasing (or constant) from the top to the bottom. Core T6 shows a very different behavior, with appreciable oscillations in the range $0.04 \%$ to $0.99 \%$, and a tendency to increase with depth. The same discontinuity observed in the TOC profile of core $\mathrm{T} 2$ is observed in the nitrogen profile at a depth of $\sim 30 \mathrm{~cm}$. The sulfur values range from $0.04 \%$ to $1.04 \%$.

Fig. 3 shows the carbon/nitrogen $(\mathrm{C} / \mathrm{N})$ and carbon/sulfur $(\mathrm{C} / \mathrm{S})$ ratios in the sediment cores. The $\mathrm{C} / \mathrm{N}$ ratio varies between 6.1 and 14.7 in the sediment cores. The $\mathrm{C} / \mathrm{S}$ ratio, varying from 1.13 to 29.40 .

Table 1 shows the depth of the statistically significant intervention revealed by the ARIMA analysis. As can be seen in the table, the intervention was significant $(p<0.05)$ for all the measured elements and ratios, at all sites except T5. However, the depth of this intervention varied considerably from site to site. Assuming the implementation of the refinery was the cause of the alteration in the sedimentation patterns, these results indicate different sedimentation rates at different sampling sites. The lack of fit at site T5 is probably due to the discharge from the river Subaé, which generates a greater amount of fluvial sediment near its estuary (Fig. 1) and induces a higher variability in the sedimentation regimes.

A more complete understanding of the intervention and sedimentation patterns in the six cores was obtained by the ARIMA analysis of the $\mathrm{C}, \mathrm{N}, \mathrm{C} / \mathrm{N}$, and $\mathrm{C} / \mathrm{S}$ ratios. This showed that, according to the $\mathrm{C}, \mathrm{N}, \mathrm{C} / \mathrm{N}$, and $\mathrm{C} / \mathrm{S}$ ratios of the sites closer to the refinery (T1, T2, and T3), the intervention occurred at similar depths, 

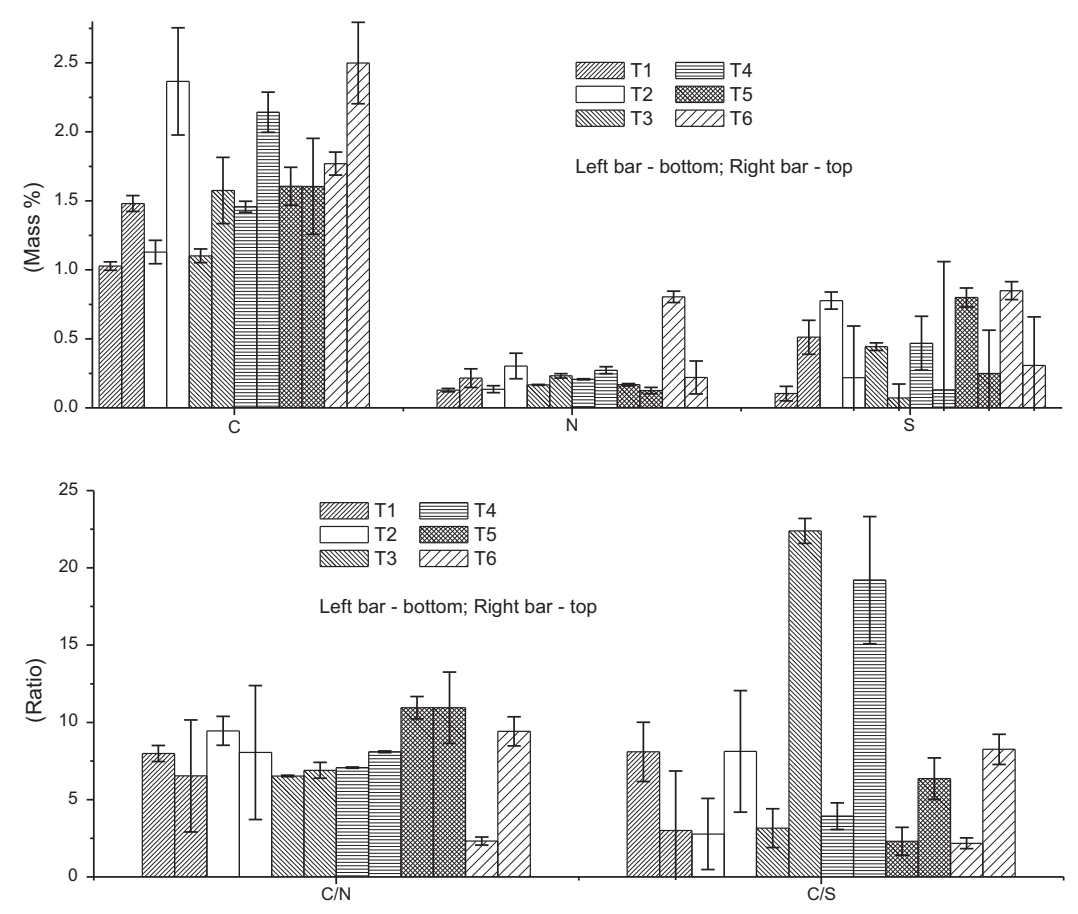

Fig. 4. Intercept and final value from Interrupted Time Series ARIMA (Intervention Analysis) of elemental analysis results.
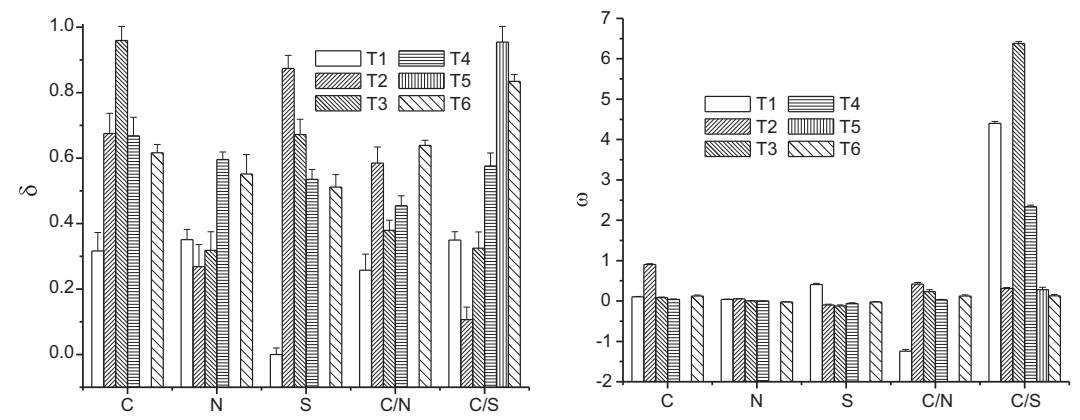

Fig. 5. Rate, $\delta$, (Right) and magnitude, $\omega$, (Left) of the asymptotic change in level after intervention.

$30-35 \mathrm{~cm}$ (Table 1), indicating a similar sedimentation rate of 6-7 $\mathrm{mm} \mathrm{y}^{-1}$, which accords with data from the literature (Argollo, 2001). However, at sites T5 and T6, the intervention was found at a depth of 60-62.5 cm (according to discontinuities in the organic matter contents of $\mathrm{C}, \mathrm{N}, \mathrm{S}$, and their respective ratios, at T6, and in the $\mathrm{C} / \mathrm{S}$ ratio at $\mathrm{T} 5$ ). This indicates a higher sedimentation rate at sites T5 and T6 (12-12.5 $\left.\mathrm{mm} \mathrm{y}^{-1}\right)$, which is consistent with an expected rate of sitting at the mouth of the river (Fig. 1). The NMR data corroborate this statement, with higher terrestrial organic matter signals in samples $\mathrm{T} 5$ and T6. Finally, the $\mathrm{C}$ and $\mathrm{C} / \mathrm{N}$ ratio at site T4 showed an intermediate value for the depth of the significant intervention $(45-47.5 \mathrm{~cm})$, which corresponds to a sedimentation rate of $9-9.5 \mathrm{~mm} \mathrm{y}^{-1}$, reflecting its intermediate position in the bay.

The $S$ and $C / S$ ratio (Figs. 2 and 3 ) showed some peculiarities. At site $\mathrm{T} 1$ and $\mathrm{T} 4$, the intervention was detected at a shallower depth $(17.5-22.5 \mathrm{~cm})$ than at the other sites. However, at site T1, a second, deeper intervention $(27.5-30 \mathrm{~cm})$, coincident with the main event at $\mathrm{T} 2$ and $\mathrm{T} 3$, was detected for the $\mathrm{C} / \mathrm{S}$ ratio; furthermore, the later (shallower) intervention at site T1 showed an inverted result: this is the only site with a sharp rise in the $S$ content and a corresponding fall in the $\mathrm{C} / \mathrm{S}$ ratio (Fig. 3). This differentiated behavior of the $S$ is probably due to human activity.
Analyzing the $\mathrm{C}$ contents, except at site $\mathrm{T} 5$, where the value was constant, there was a significative increase towards the top of each core; i.e. higher $C$ contents in more recent deposits (Fig. 4). The bottom samples of the cores at the sites closer to the refinery (T1, T2, and T3) exhibited lower values and they were statistically equal within this group. In contrast, at the sites closer to the river mouth (T5 and T6), the initial C contents (bottom samples of the cores) were higher than at the other sites and equal to each other. Again, the core bottom at site T4 showed an intermediate value and was statistically different from the above mentioned groups. The greatest increase from bottom to top is observed at site T2, the closest to the refinery (Fig. 4), where the recent $C$ content is significantly higher than the others in the local group (T1 and T3).

An interesting feature found in Fig. 4 is that although an increase is seen in the $\mathrm{N}$ contents at $\mathrm{T} 1, \mathrm{~T} 2, \mathrm{~T} 3$, and $\mathrm{T} 4$, upon the implementation of the refinery, in the samples closer to the river mouths (T5 and T6), there is an increase in the $\mathrm{N}$ content with depth. As for the $C$ contents, the greatest increase is observed at site T2.

Except for T1, all recent cores present a smaller $\mathrm{S}$ content than the older ones, being not significant for core T4 due to a high standard deviation for the upper T4 core. In T1 cores the S content was great in the recent core. 

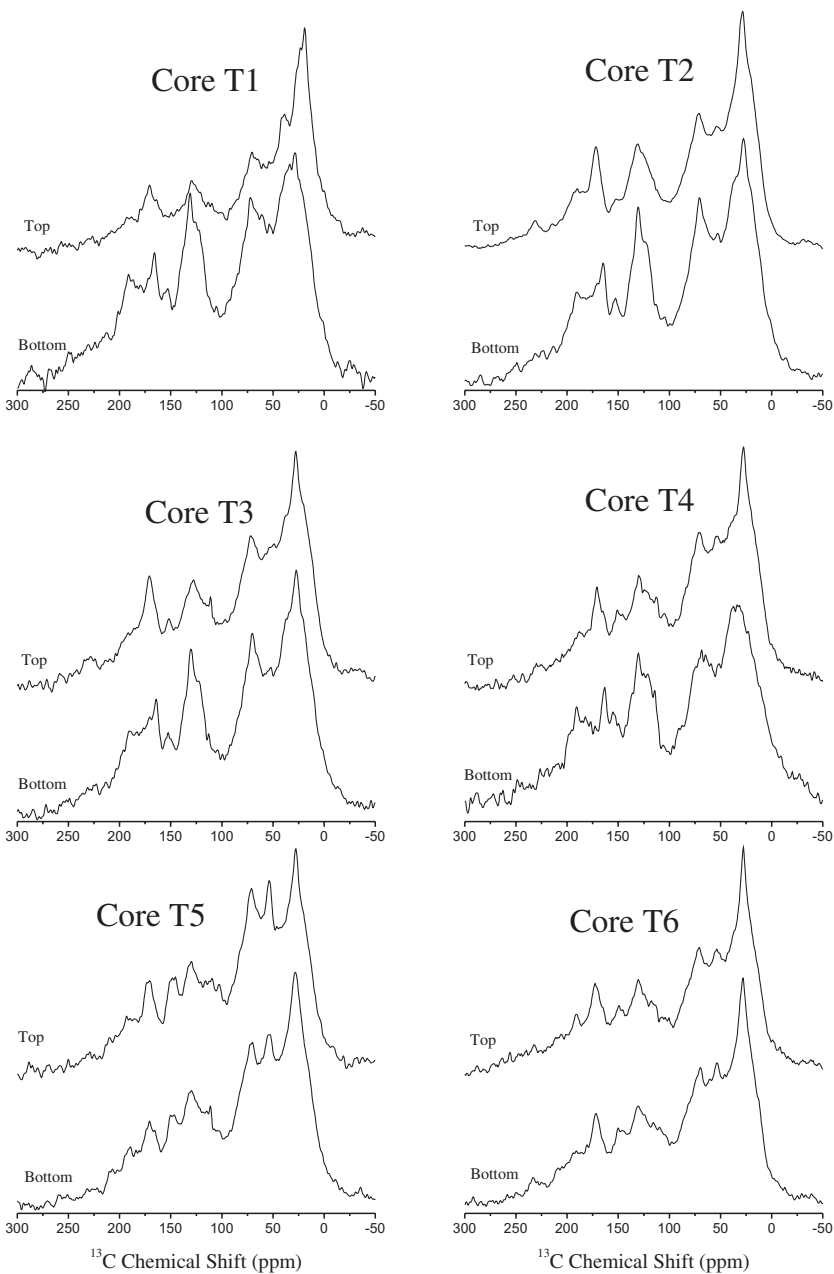

Fig. 6. ${ }^{13} \mathrm{C}$ ramped-CP/MAS spectra of sediments.

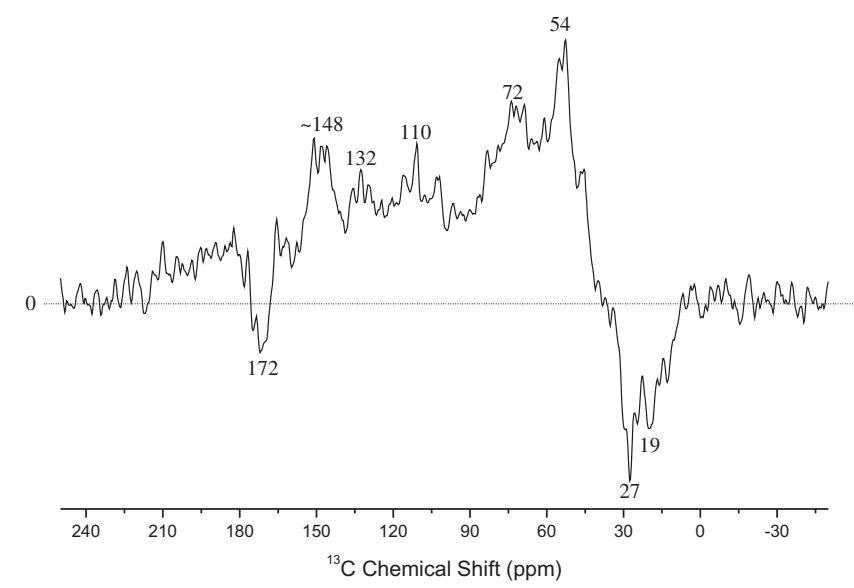

Fig. 7. First PC analyzes of sediments cores.

Several authors have suggested distinct ranges of $\mathrm{C} / \mathrm{N}$, according to the origin of the organic matter. Saito et al. (1989) suggested a ratio higher than 20 for organic matter from a terrestrial origin and between 5 and 7 from a pelagic (marine) source. In addition, Stein (1991) reported that values of $\mathrm{C} / \mathrm{N}$ lower than 10 point to a strictly marine origin and values around 10 represent mixed marine and terrestrial organic components in the sediment. Except for the cores T6 (2.3 at bottom), T1 (6.5 at top), and T3 (6.9 and 6.5, at

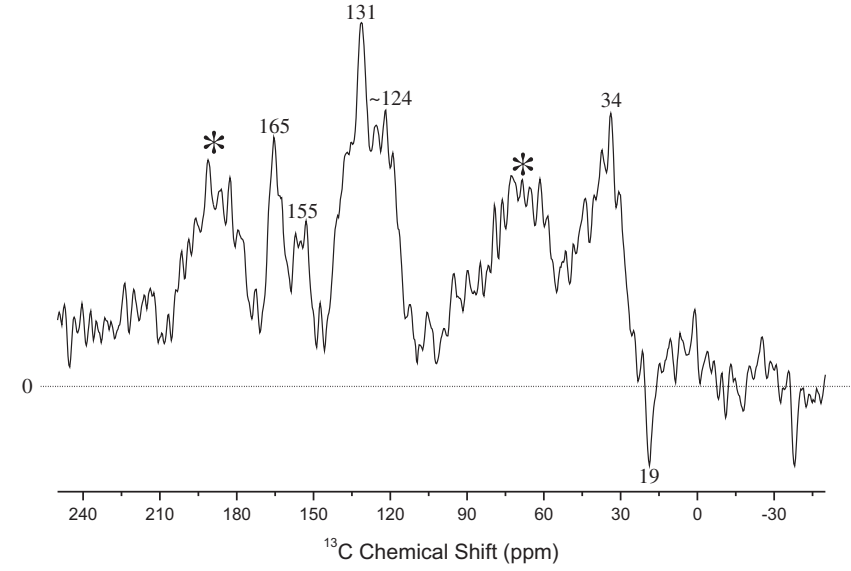

Fig. 8. Second PC analyzes of sediments cores (* Spinning sidebands).

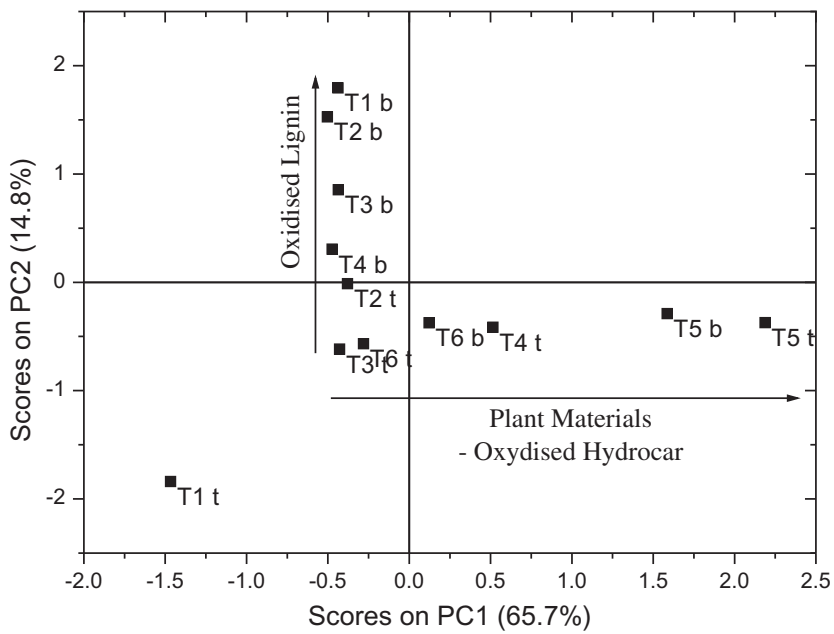

Fig. 9. Scores of first $\mathrm{PC}(\mathrm{PC} 1)$ versus second $\mathrm{PC}(\mathrm{PC} 2) . \mathrm{b}=$ bottom core; $t=$ top

top and bottom, respectively), whose $\mathrm{C} / \mathrm{N}$ ratios indicate a marine source, all the cores under study are in the range of a mixed marine-terrestrial origin, similar to the results of Burone et al. (2003), analyzing surface sediments in Ubatuba bay, Brazil (6.00-16.56). Sometimes, inorganic nitrogen brought by the discharge of sewage can contribute to lowering the $\mathrm{C} / \mathrm{N}$ ratio. This probably explains the atypical value found for the lower core T6, collected close to the Subaé River. By for the largest rise in the $\mathrm{C} / \mathrm{N}$ ratio from the bottom to the top of the core was observed at site T6 (Fig. 4).The C/S ratio (Fig. 4) is larger at the top of each core, except at sites T1 and T2, where the changes were not significant. The largest increases were observed at sites T3 and T4. In contrast for the recent cores, at T1, $\mathrm{C} / \mathrm{S}$ was the smallest of any core, but statistically equals the ratio at the top of T2 and T5. It should be stressed that the initial (bottom) $\mathrm{C} / \mathrm{S}$ ratio at T1 was the largest among the core bottoms. Leventhal (1983) and Berner (1989) stated that the ratio of the organic carbon to the sulfur content $(C / S)$ could help to distinguish between an oxygenated and an anoxic environment. According to these authors, ratios lower than 2.8 are indicative of sediments tending to anoxic conditions. The present values for the $\mathrm{C} / \mathrm{S}$ ratio vary from 1.8 to 29.7, the ratio decreasing with depth in almost all cores. The exception found for core T1, where lower values (although not significant) were found at the top, is attributed to the anomalously high recent sulfur content. Most of our core bottoms are below 2.8, corresponding to anoxic conditions. Regarding the kinetics of the 
alterations, represented by the parameters $\omega$ and $\delta$ (Fig. 5), the impact was more abrupt (smaller $\delta$ ) for $\mathrm{C}$, and especially $\mathrm{S}$, at site $\mathrm{T} 1$, being $S$ the only parameter and site where the modelled intervention was abrupt and permanent. For the $\delta$ parameter, the variable that best discriminated the position of the samples in the bay was $\mathrm{N}$, whose $\delta$ values were smaller at the sites closer to the refinery; this aboutness was due to proximity and the lower sedimentation rates at these sites.

The $\omega$ parameter, the rate of the change after the intervention, was largest, in absolute value, for the second event at site T1 for the $\mathrm{C} / \mathrm{S}$ ratio (-16.2, data not showed), resulting in a rapid decrease in the value of $C / S$. After that, the largest rates $(\omega)$, were observed for the variables $\mathrm{C}, \mathrm{N}$ and $\mathrm{C} / \mathrm{N}$ at the $\mathrm{T} 2$ site, $\mathrm{S}$ at T1 and $\mathrm{C} / \mathrm{S}$ at T3. Both kinetic parameters ( $\delta$ and $\omega$ ) indicated that the changes were faster and more intense at the sites closer to the refinery.

\section{2. ${ }^{13} \mathrm{C}$ NMR spectroscopy}

Fig. 6 shows the ${ }^{13} \mathrm{C}$ spectra obtained using ramped-CP/MAS technique (Knicker et al., 2005) of the organic matter extracted from the top and bottom of each core.

A typical ${ }^{13} \mathrm{C}$ ramped-CP/MAS NMR spectrum of marine sediments exhibits pronounced peaks in the aliphatic region, accounting for $50 \%$ of the total carbon, the rest of the carbons being eventually distributed among aromatic, carbohydrate and carboxyl structures. The lignin content of coastal sediments is reported to be approximately 3-5\% (Hedges and Oades, 1997).

The ${ }^{13} \mathrm{C}$ ramped-CP/MAS spectra of the cores studied in this work (Fig. 6) show large amounts of aliphatic carbon in these sediments. Thus, all the cores are typical of coastal sediment. Cores T5 and T6 contain higher contribution from lignin, evident from higher methoxyl carbon (56 ppm) and aromatic carbon (112-160 ppm) signals. T5 and T6 are the cores closest to the mouth of the Subaé River, which contributes terrestrial organic matter.

The first two PCs extracted from the ${ }^{13} \mathrm{C}$ ramped-CP/MAS NMR spectra accounted for $80.5 \%$ of the total variance and provided a reasonable separation of the sample set, but an oriented orthogonal rotation of these factors (vectors) was performed in order to maximize the contrasts of interest, i.e. the separation of older and newer (bottom and top) sediments and the locations of the cores in the studied area.

The first PC, PC1 (Fig. 7), derived from the NMR spectra captured $65.7 \%$ of the total variance. It shows the highest positive loadings in the spectral region of groups that probably originate from plant materials, such as lignin $(148,132$, and $54 \mathrm{ppm})$ and cellulose (110 and $72 \mathrm{ppm}$ ) and negative loadings possibly from oxidized hydrocarbons and/or fatty acids (172 ppm and alkyl region).

For the PC2 (14.8\% of the total variance), shown in Fig. 8 , the spectral regions with higher loadings were those associated with partially oxidized lignin: $165 \mathrm{ppm}$ - probably carboxyl groups attached to aromatic structures; $155 \mathrm{ppm}$ - probably from phenolic groups, since they do not have the corresponding methoxyl signal at $54 \mathrm{ppm}$ from unaltered lignin, and the aryl groups and their spinning sidebands.

The scores of each sample on PC1 versus PC2 are plotted on the ordination chart in Fig. 9. The scores on PC1 clearly differentiate the sediment samples closer to the Subaé estuary, specially the sample $\mathrm{T} 5$, with a higher content of terrestrial organic matter delivered by the river and a lower content (negative loading) of oil hydrocarbons. The higher content of the latter compounds in the samples closer to the refinery is indicative of pollution, resulting in the observed small scores for these sites (T1, T2, T3, and T4).

On the other hand, the scores on PC2 increase from top to bottom, in the cores closer to the refinery, characterizing a change in the regime of organic sedimentation between the periods before and after the refinery was implanted. The older sediments produced signals typical of partially oxidized lignin (positive loadings). The negative loadings at $19 \mathrm{ppm}$, on both PCs, differentiate the T1 top sample, which had a strong signal in this region, from all other samples.

\section{Conclusions}

The results of elemental analysis of cores T1, T2, and T3, particularly in the TOC content, suggest an abrupt change in the sedimentation regime around a depth of $30-35 \mathrm{~cm}$. Using the sedimentation rate of $7 \mathrm{~mm} \mathrm{y}^{-1}$ reported by Argollo (2001) for this area, this depth corresponds to about 50 years ago, when the industrial activity started in the region. For core T4, there is no indication of a change in the sedimentation regime. Cores $\mathrm{T} 5$ and T6 show a distinct pattern of sedimentation, indicating the influence of material carried by the Subae River. At these sites, the velocity of sedimentation is probably higher, varying with the discharge from the river. This higher input from terrestrial organic matter is corroborated by the NMR data (a pronounced methoxyl peak from lignin in the T5 sample).

The sulfur content of the samples increased with depth in the cores, except in core T1, where it decreased, and T4, which showed a high variability, so that the result was not statistically significant at $5 \%$. For all cores, except T1 and T2, whose differences were not statistically significant at $5 \%$, the $\mathrm{C} / \mathrm{S}$ ratios decreased with depth, reaching values below 2.8 , characteristic of anoxic environments.

The data from the ${ }^{13} \mathrm{C}$ ramped-CP/MAS measurements led to the conclusion that all our cores had large amounts of aliphatic carbon, typical of coastal sediments. The T5 core contained a higher contribution derived from lignin, evident in the higher methoxyl carbon (54 ppm) and aromatic carbon signal (112-160 ppm). The T6 core also shows a visible contribution from lignin. This result is clearly shown by PCA, which also showed a higher content of hydrocarbon oil in the samples closer to the refinery, indicating environmental pollution. The change in the organic matter composition, following refinery implementation, is revealed by PC2, the older (deeper) samples being richer in partially oxidized lignin than the newer ones. The negative loadings at $19 \mathrm{ppm}$, on both PCs, differentiate the $\mathrm{T} 1$ top sample, which gave a stronger signal in this region.

\section{Acknowledgements}

Financial support was provided by "Conselho Nacional de Desenvolvimento Científico e Tecnológico - CNPq”, "Coordenação de Aperfeiçoamento de Pessoal de Nível Superior - CAPES" and "Fundação de Amparo à Pesquisa do Estado de São Paulo" - FAPESP. Authors acknowledge Dr. Ruy Kenji Papa de Kikuchi and Dr. Guilherme Lessa for their help in the sample collection.

\section{References}

Argollo, R.M., 2001. Cronologias de sedimentação recente e de deposição de metais pesados na Baía de Todos os Santos usando ${ }^{210} \mathrm{~Pb}$ e ${ }^{137} \mathrm{Cs}$. PhD Thesis. Curso de Pós Graduação em Geofísica. Universidade Federal da Bahia, Salvador.

Berner, R.A., 1989. Biogeochemical cycles of carbon and sulfur and their effect on atmospheric oxygen over Phanerozoic time. Paleogeography, Paleoclimate and Paleoecology 75, 97-122.

Bordovsky, O.K., 1965. Accumulation of organic matter in bottom sediments. Marine Geology 3, 33-82.

Burone, L., Muniz, P., Pires-Vanin, A.M.S., Rodrigues, M., 2003. Spatial distribution of organic matter in the surface sediments of Ubatuba Bay (Southeastern-Brazil). Annals of the Brazilian Academy of Sciences 75 (1), 77-90.

Cook, R.L., Langford, C.H., Yamdagni, R., Preston, C.M., 1996. A modified crosspolarization magic angle spinning ${ }^{13} \mathrm{C}$ NMR procedure for the study of humic materials. Analytical Chemistry 68, 3979-3986.

Dria, K.J., Sachleben, J.R., Hatcher, P.G., 2002. Solid-state carbon-13 nuclear magnetic resonance of humic acids at high magnetic field strengths. Journal of Environmental Quality 31, 393-401.

Gélinas, Y., Baldock, J.A., Hedges, J.I., 2001. Demineralization of marine and freshwater sediments for $\mathrm{CP} / \mathrm{MAS}{ }^{13} \mathrm{C}$ NMR analysis. Organic Geochemistry $32,677-693$. 
Hedges, J.I., Oades, J.M., 1997. Review Paper - Comparative organic geochemistry of soils and marine sediments. Organic Geochemistry 27, 319-361.

Knicker, H., Totsche, K.U., Almendros, G., González-Vila, F.J., 2005. Condensation degree of burnt peat and plant residues and the reliability of solid-state VACP MAS ${ }^{13} \mathrm{C}$ NMR spectra obtained from pyrogenic humic material. Organic Geochemistry 36, 1359-1377.

Leventhal, J.S., 1983. An interpretation of carbon and sulfur relationships in Black Sea sediments as indicators of environments of deposition. Geochemical, Cosmochemical Acta 47, 133-137.

Novotny, E.H., Blum, W.E.H., Gerzabek, M.H., Mangrich, A.S., 1999. Soil managemen system effects on size fractionated humic substances. Geoderma 92, 87-109.

Novotny, E.H., Knicker, H., Martin-Neto, L., Azeredo, R.B.V., Hayes, M.H.B., 2008 Effect of residual vanadyl ions on the spectroscopic analysis of humic acids: a multivariate approach. European Journal of Soil Science 59, 439-444.
Patience, R.L., Wilson, M.A., 1990. Practical applications of solid state ${ }^{13} \mathrm{C}$ NMR to the structural elucidation of sedimentary organic matter. Trends in Analytical Chemistry 9 (1), 26-31.

Peersen, O.B., Wu, X., Kustanovich, I., Smith, S.O., 1993. Variable-amplitude crosspolarization MAS NMR. Journal of Magnetic Resonance 104, 334-339.

Ryba, S.A., Burgess, R.M. 2002. Effects of sample preparation on the measurement of organic carbon, hydrogen, nitrogen, sulfur and oxygen concentrations in marine sediments. Chemosphere 48, 139-147.

Saito, Y., Nishimura, A., Matsumoto, E., 1989. Transgressive sand sheet covering the shelf and upper slope off Sendai, Northeast Japan. Marine Geology 89, $245-258$.

Stein, R., 1991. Accumulation of organic carbon in marine sediments. Results from the Deep Sea Drilling Project/Ocean Drilling Program. Lecture Notes in Earth Sciences, vol. 34. Springer-Verlag, Berlin (pp. 217) 